\title{
EDUCAÇÃO INCLUSIVA E A PARTICIPAÇÃO DOS PAIS NA APRENDIZAGEM DOS ALUNOS COM DEFICIÊNCIA
}

\section{INCLUSIVE EDUCATION AND PARENT PARTICIPATION IN LEARNING STUDENTS WITH DISABILITIES}

\author{
$10.31072 /$ rcf.v12i2.957
}

Danieli Moreira M. Talau

Graduanda em Direito pela Faculdade de Educação e Meio Ambiente - FAEMA.

E-mail: danieli.37260@faema.edu.br.

\section{Eloiza Carvalho Feitosa}

Graduanda em Direito pela Faculdade de Educação e Meio Ambiente - FAEMA.

E-mail: eloiza.37275@faema.edu.br.

Hellen Talita B. V. Santos Graduanda em Direito pela Faculdade de Educação e Meio Ambiente - FAEMA. E-mail: hellen.37044@faema.edu.br.

Gabriela de Oliveira Souza

Graduanda em Direito pela Faculdade de Educação e Meio Ambiente - FAEMA.

E-mail: gabriela.48451@faema.edu.br.

Ingrid Gabriela F. dos Santos Graduanda em Direito pela Faculdade de Educação e Meio Ambiente - FAEMA.

E-mail: ingrid.40485@faema.edu.br.

\section{Railton Costa Peixoto}

Graduando em Direito pela Faculdade de Educação e Meio Ambiente - FAEMA.

E-mail: railton.38260@faema.edu.br

Zieli Pereira dos Santos

Graduanda em Direito pela Faculdade de Educacão e Meio Ambiente - FAEMA.

E-mail: zieli.43822@faema.edu.br.

\section{Hudson Carlos A. Persch}

Coordenador e Professor de curso de graduação em Direito. Mestrando em Direito na Universidade de Marília - UNIMAR. E-mail: hudsonpersch@hotmail.com.
Resumo: A educação inclusiva teve grande crescimento na década de 90 e teve como base garantir ao aluno com deficiência o ingresso e participação nas atividades educacionais, contudo, verificou-se a dificuldade na sua inserção no ambiente escolar. Os objetivos foram pautados no sistema educacional brasileiro frente à inclusão dos alunos com deficiência, a comparação do tratamento que estes alunos recebem no ensino público e privado e, se os mecanismos de ensino e recursos materiais necessários para a vida escolar são, de fato, capazes de garantirem o aprendizado destes alunos. Além disso, analisou-se a transformação do sistema educacional com relação aos alunos com deficiência e a participação dos que o cercam. Para essa pesquisa utilizou-se a abordagem qualitativa, que buscou compreender o fenômeno da educação inclusiva. Nos objetivos da metodologia aplicada optou-se pelo método descritivo, ao qual buscou descrever a realidade escolar a partir do ingresso de alunos com deficiência. Por fim, aplicou-se a pesquisa bibliográfica com o fito de fundamentar a percepção prática encontrada no seio escolar e familiar, para tanto, utilizou-se livros, artigos científicos, bem como a legislação vigente no ordenamento jurídico brasileiro. Teve como resultados prévios a importância da disponibilidade dos materiais didáticos para os alunos com deficiência, a preparação das instituições de ensino no que se refere a acessibilidade, capacitação dos docentes, contratação de equipe de apoio e de profissionais especializados, apoio escolar para com as famílias, e a participação da sociedade na inclusão dos alunos deficientes nas escolas.

Palavras-chave: Deficiência. Educação inclusiva. Educador especial. Familiares.

Abstract: Inclusive education had great growth in the 1990s and was based on guaranteeing students with disabilities to enter and participate in educational activities, however, there was a difficulty in their insertion in the school environment. The objectives were based on the Brazilian educational system regarding the inclusion of students with disabilities, the comparison of the treatment these students receive in public and private education, and whether the teaching mechanisms and material resources necessary for school life are, in fact, capable to ensure the learning of these students. In addition, the transformation of the educational system in relation to students with disabilities and the participation of those around it was analyzed. For this 
Submetido: 8 jun. 2021.

Aprovado: 8 ago. 2021.

Publicado: 9 ago. 2021.

E-mail para correspondência:

hudsonpersch@hotmail.com

Este é um trabalho de acesso aberto e distribuído sob os Termos da Creative Commons Attribution License. A licença permite o uso, a distribuição e a reprodução irrestrita, em qualquer meio, desde que creditado as fontes originais. Imagem: StockPhotos (Todos os direitos reservados).

Open Access research, a qualitative approach was used, which sought to understand the phenomenon of inclusive education. In the objectives of the methodology applied, the descriptive method was chosen, which sought to describe the school reality based on the admission of students with disabilities. Finally, bibliographical research was applied in order to substantiate the practical perception found in the school and family environment, for that, books, scientific articles, as well as the current legislation in the Brazilian legal system were used. Previous results were the importance of the availability of teaching materials for students with disabilities, the preparation of educational institutions with regard to accessibility, teacher training, hiring of support staff and specialized professionals, school support for families, and the participation of society in the inclusion of students with disabilities in schools.

Keywords: Deficiency. Inclusive education. Special educator. Relatives.

Introdução

O presente artigo tem como enfoque a educação dos alunos com deficiência nas redes de ensino, tanto no estado de Rondônia, como no Brasil. Tal preocupação se caracteriza pela dificuldade da assistência a estes alunos, em como os pais e os professores participam do ambiente escolar, como é o trabalho do educador especial, bem como, se todas as instituições, que possuem alunos com deficiência, tem em seu quadro de funcionários, a equipe de apoio necessária e qualificada, e se recebem recursos pedagógicos necessários para a inclusão.

Inicialmente será analisado o desenvolvimento da educação inclusiva no Brasil, além da participação da família no ambiente escolar e como os alunos de escolas públicas lidam com a falta de estruturas ou com os programas de inclusão. Em seguida, será feito uma análise da legislação brasileira, do que é a educação e a inclusão, verificando os dados de implementação de programas inclusivos no estado de Rondônia, e o papel do educador especial em sala de aula.

Os objetivos estarão pautados na identificação das leis e programas de educação inclusiva, bem como compreender o papel do educador especial e da família no ambiente de ensino, para que seja possível entender o funcionamento do sistema educacional brasileiro e a inclusão de alunos com deficiência, além de 
analisar como é a realidade dos alunos da rede pública e descrever quais os mecanismos de ensino e recursos pedagógicos oferecidos às instituições para que possam acolher os alunos com deficiência.

Ao decorrer do artigo será possível constatar: a transformação do sistema educacional inclusivo, participação familiar, legislação, a relação do educador especial com o aluno, e ainda, como o acolhimento e o apoio são importantes na inclusão, aprendizado e desenvolvimento destes alunos.

Para a composição do presente artigo será demonstrado o aprimoramento da acessibilidade das instituições de ensino, assinalando o direito de qualquer pessoa ter acesso à educação, sem qualquer distinção, conforme descrito na Constituição Federal de 1988, demonstrando a quantidade de escolas beneficiadas com o programa de escola acessível no estado de Rondônia, o impasse da adaptação dos docentes aos conteúdos e as metodologias aplicadas.

Para essa pesquisa será utilizada a abordagem qualitativa, que buscará compreender o fenômeno da educação inclusiva. Nos objetivos da metodologia aplicada através do método descritivo, será possível descrever a realidade escolar a partir do ingresso de alunos com deficiência. Por fim, será aplicada a pesquisa bibliográfica com o fito de fundamentar a percepção prática encontrada no seio escolar e familiar, para tanto, serão utilizados livros, artigos científicos e a legislação vigente no ordenamento jurídico brasileiro.

Inicialmente é possível notar as mudanças no sistema educacional dos alunos com deficiência, pois, a legislação analisou e implantou programas de incentivo a inclusão destes tanto na rede pública quanto na rede privada, além da preocupação em capacitar profissionais para que pudessem acompanhá-los e melhor assisti-los, além de incluir os familiares neste processo. Outro fato de suma importância é a elaboração e disponibilização de materiais didáticos de fácil compreensão, e a entrega de materiais de apoio para que o aluno possa ter em casa os recursos necessários para seu aprendizado. 


\section{Metodologia}

Nessa pesquisa foi utilizado a abordagem qualitativa, que buscou entender o fenômeno da educação inclusiva, uma vez que a pesquisa qualitativa busca compreender fenômenos sociais, buscando deles alcançar um espectro detalhado e complexo por meio de uma análise científica do pesquisador (1).

Nos objetivos da metodologia aplicada optou-se pelo método descritivo, ao qual buscou descrever a realidade escolar a partir do ingresso de alunos com deficiência, identificando e descrevendo a importância do envolvimento dos educadores especiais, dos pais, dos demais alunos e da sociedade num todo, buscando aprofundar os conhecimentos já descritos em artigos e demais documentos utilizados para o desenvolvimento deste trabalho ${ }^{(2)}$.

Por fim, aplicou-se a pesquisa bibliográfica com o fito de fundamentar a percepção prática encontrada no seio escolar e familiar, para tanto, utilizou-se livros, artigos científicos, bem como a legislação vigente no ordenamento jurídico brasileiro. Esse tipo de pesquisa permite que seja estabelecido uma ligação dos dados teóricos colhidos e assim obter maiores conhecimentos acerca de determinado tema (3).

\section{Resultados e Discussão}

O pedagogo francês Célestin Freinet é identificado como um dos educadores da Escola Nova, que surgiu nas primeiras décadas do século XX, contrariando o ensino tradicionalista, propondo uma educação ativa. Para ele as atividades direcionam a prática escolar, e o objetivo final da educação é formar cidadãos que trabalhem livre e criativamente, dominando e transformando o meio em que vive e libertar quem o faz ${ }^{(4)}$. 
Diante desse fato, é importante salientar que o desenvolvimento das estratégias de ensino e inclusão, proporciona a todos os alunos, sem qualquer diferença, resultados mais benéficos na absorção das matérias ministradas em sala de aula e, em face disto, observa-se que a transformação e desenvolvimento do sistema educacional beneficia cada vez mais o saber dos alunos.

A história das escolas inclusivas no Brasil teve uma evolução a partir da década de 90 (noventa). A educação especial vem se adaptando desde 1854, tendo início na época do Império com a criação de duas instituições: o Imperial Instituto dos Meninos Cegos, em 1854, atualmente como Instituto Benjamin Constant - IBC, e o Instituto dos Surdos Mudos, em 1857, hoje conhecido como Instituto Nacional da Educação dos Surdos, ambos no Rio de Janeiro, que ao longos dos anos possibilitaram o surgimento de outros institutos de atendimento especializado às pessoas com deficiência (5). Contudo, muitos têm acesso parcial à educação e em alguns lugares não aceitam pessoas com deficiência pela falta de um ambiente escolar propício para esses alunos, sendo então privados de ter acesso a um ambiente escolar ${ }^{(6)}$. Um sistema educacional inclusivo encontra-se amparado legalmente, na Constituição Federal de 1988 que implementa em seu artigo 208, III, sobre o dever do Estado com a educação inclusiva, garantindo atendimento educacional especializado aos portadores de deficiência ${ }^{(7)}$.

A educação inclusiva está ligada aos direitos de as pessoas com deficiência terem acesso a uma educação de qualidade com a participação do Estado, gestores e professores. Embora ainda seja de difícil acesso para muitos, as escolas vêm se aprimorado para exercer a inclusão de todos e valorizar a diversidade dos estudantes, para que possam aprender juntos e sem nenhum tipo de discriminação (8). 
A educação inclusiva relacionada aos alunos especiais carece de um tratamento diferente aos demais alunos, tais como recursos adaptados e inclusivos, plano pedagógico diferenciado, para que a aprendizagem seja de qualidade, valorizando a diversidade para acolher todo tipo de aluno com necessidade educacional, já que muitos não têm recursos no próprio ambiente familiar.

Princípio fundamental da escola inclusiva é o de que todas as crianças devem aprender juntas, sempre que possível, independentemente de quaisquer dificuldades ou diferenças que elas possam ter. Escolas inclusivas devem reconhecer e responder às necessidades diversas de seus alunos, acomodando ambos os estilos e ritmos de aprendizagem e assegurando uma educação de qualidade à todos através de um currículo apropriado, arranjos organizacionais, estratégias de ensino, uso de recurso e parceria com as comunidades. ${ }^{(9)}$

As escolas devem estar preparadas para incluir esses alunos com deficiência na programação escolar, além de ter conhecimento dos materiais necessários, ser capaz de identificar as necessidades dos alunos, independentes de sua deficiência, para que assim o professor atenda às condições de cada aluno. No entanto, a falta de contratação de profissionais especializados é também um dos desafios encontrados, pois, na maioria dos casos, esses alunos requerem assistência especializada, que vai além da capacitação dos professores, estes que geralmente não tem domínio sobre todos os recursos destinados às mais variadas deficiências.

Embora ainda existam desafios inerentes a inclusão dos alunos com deficiência, avanços também são registrados, nas escolas públicas ou particulares, um destes exemplos é o ambiente físico para maior acessibilidade de locomoção para alunos com deficiência física, de modo que, se sintam incluídos e seguros na escola. Dados abaixo mostram como as escolas têm se preparado para receber esses alunos, tornando o ambiente escolar mais propício e inclusivo. 
Tabela 01: Aprimoramento da infraestrutura das instituições de ensino. ${ }^{(10)}$

\begin{tabular}{|l|l|}
\hline Ensino Fundamental - Escolas Públicas & Ensino Fundamental - Escolas Particulares \\
\hline Banheiros Adaptados - 38,6\% & Banheiros Adaptados - 55,6\% \\
\hline Dependências Adequadas - 28\% & Dependências Adequadas - 47,7\% \\
\hline Ensino Médio - Escolas Públicas & Ensino Médio - Escolas Particulares \\
\hline Banheiros Adaptados - 60\% & Banheiros Adaptados - 68,7\% \\
\hline Dependências Adequadas - 44,3\% & Dependências Adequadas - 52,7\% \\
\hline
\end{tabular}

Como mostrado acima, as escolas aprimoraram suas instalações de acordo com as dificuldades encontradas para que a acessibilidade seja assegurada mediante a eliminação de barreiras presentes nestes locais, pois além de um plano pedagógico adaptado, um atendimento educacional especializado, a locomoção desses alunos também faz parte da inclusão para uma melhor convivência no ambiente escolar. Ademais, cabe aos sistemas de ensino organizar e fornecer monitoria, instruções, tradutor/intérprete de Libras, cuidadores para que possam se locomover a outros setores das instituições, tendo em vista que necessitam de auxílio constantemente nas dependências escolares.

A inclusão das pessoas com deficiências modifica o sistema educacional, tornando-se versátil, já que a elas são ofertadas a possibilidade da inclusão, propiciando oportunidades tanto na vida acadêmica quanto profissional. Entretanto, alguns ainda têm dificuldades de se inserir no meio de trabalho por falta de logística e adaptações das empresas. No processo de construção inclusiva no ambiente escolar, as escolas carecem de se atualizar, buscar fornecer materiais de apoio e professores capacitados para ajudar pessoas com deficiências terem uma experiência acadêmica de qualidade, proporcionando melhores condições de aprendizagem ${ }^{(11)}$. 
É interessante certificar-se de que tipo de aprendiz é o aluno, se é visual, auditivo ou cinestésico. Alunos visuais precisam de cartões com figuras, imagens, materiais para contar, ou seja, todo tipo de material que possa ser visto o auxiliará na aprendizagem. A grande maioria das pessoas são visuais. 0 aluno auditivo aprende melhor ouvindo. Para um aluno auditivo, é válido gravar histórias, trechos de livros etc. 0 aluno cinestésico precisa tocar nos objetos para aprender. Para o cinestésico, vale o uso de objetos e materiais pedagógicos táteis para facilitar sua aprendizagem. ${ }^{(12)}$

Com o passar dos anos o Brasil está implementado cada vez mais leis que promovem o acompanhamento e assistências aos alunos com deficiência, inclusive, em 1994, a educação inclusiva no Brasil passou a fundamentar-se com a Conferência Mundial sobre Necessidades Educacionais: Acesso e Qualidade, que ocorreu na Espanha, sendo então proclamada a Declaração de Salamanca. No mesmo ano foi publicada a Política Nacional de Educação Especial, mantendo a responsabilidade da educação dos alunos deficientes no âmbito da educação especial. (5)

Desse modo, entendemos que, a educação inclusiva deve basear-se no princípio da igualdade e equidade, recebendo os materiais necessários para cada tipo de dificuldade encontrada, garantindo direitos a todos sem qualquer tipo de discriminação, para que frequentem às salas regulares de ensino desfrutando dos mesmos direitos e oportunidades ao acesso à informação e a educação, independentemente de suas dificuldades locomotivas, intelectuais, auditivas ou visuais.

$\mathrm{Na}$ atualidade é fundamental que o trabalho realizado para alunos com deficiência, tanto em escolas particulares, quanto em escolas públicas, seja positivo. É imprescindível que esses estudantes sejam incluídos, e principalmente que a absorção dos conteúdos ministrados em sala de aula, obedecendo as limitações, seja satisfatória, sendo este o resultado que a maioria dos familiares desses alunos almejam. 
Ou seja, que o conhecimento adquirido resulte num bom desenvolvimento no meio escolar, familiar e social, ainda que tenham limitações próprias da deficiência, contudo, que essas adversidades não os deixem excluídos, uma vez que, as dificuldades enfrentadas por esses alunos são diversas, todavia, essa inclusão deve ser de fato eficaz e produtiva, pois, necessitam de atenção especializada e recursos adequados a cada tipo de deficiência. E para isso a participação da família é essencial nesse processo de inclusão e ensino-aprendizagem. (13):

Segundo Amin et.al, em sua obra Curso de Direito da Criança e do Adolescente

0 art. 28 do Estatuto da Pessoa com Deficiência, incumbe ao Poder Público, dentre outras obrigações, aprimorar os sistemas educacionais, garantindo condições de acesso, permanência, participação e aprendizagem, por meio de oferta de serviços que eliminem as barreiras e promovam a inclusão plena; projeto pedagógico que institucionalize 0 atendimento educacional especializado, para atender as características dos estudantes com deficiência e garantir o seu pleno acesso ao currículo em condições de igualdade, promovendo a conquista de sua autonomia.

Assim, quanto à obrigação da participação familiar, perpassa o convívio destas com as pessoas com deficiência, faz-se necessário que sejam presentes no aprendizado estudantil e a luta pela efetivação dos seus direitos. A família da criança com deficiência representa o principal contexto de desenvolvimento, merecendo assim, a atenção das políticas públicas, das instituições de atendimento e das escolas, para poder cumprir com eficiência sua função (14) (15).

Pode-se observar que recentemente tem se tornado mais crítico a participação da família destes alunos devido à pandemia da Covid-19, tendo em vista que, as aulas são realizadas pelo Ensino Educacional à Distância (EAD), e em algumas ocasiões não possuem os recursos necessários, o que causa maiores dificuldades para alcançar o objetivo de ensino, tendo déficit de aprendizagem. 
Coube, por essa razão, aos familiares presentes adaptarem a essa metodologia de ensino, buscando meios para auxiliá-los cotidianamente, incluindo esses casos em seu dia a dia, mesmo que esse seja um trabalho exercido por profissionais especializados, a família em si também precisa abraçar de forma natural, pois esses alunos são filhos, netos, sobrinhos que carecem de apoio familiar (15).

A inclusão pelos familiares abrange um desenvolvimento que auxiliam no dia a dia destes alunos, por mais que haja obstáculos para estes familiares desenvolverem essa participação necessária, pois carecem de atenção especial, precisando ser analisada de maneira natural. A família é a unidade básica do indivíduo, a primeira responsável pelo desenvolvimento da criança em todos os sentidos: social, emocional, sensório-motor, cognitivo ${ }^{(15)}$. Assim, a família proporciona o alicerce cotidiano, e necessitam serem cautelosos em momentos mais relevantes, tornando-se prestativos e buscando adquirir conhecimentos específicos, o que poderá produzir um ensino com mais tranquilidade e confiança, possibilitando o avanço desejado por todos, visto que com o apoio da família o aluno poderá sentirse confiante.

Em vista disso, cabe ao professor, como profissional na área, esclarecer para as famílias dúvidas surgidas durante as aulas, considerar a importância da família estar incluída, organizar reuniões e atividades de reforço. É indispensável que seja constante esse auxílio aos alunos, em seus estudos, bem como aos familiares, tendo em vista a responsabilidade dos mesmo, uma vez que, também apresentam dificuldades na condução, o que exige-se atenção e maiores cuidados, necessitando de informações para se prepararem, para que o aluno não possa ser prejudicado e sentir-se abatido por essa razão, podendo promover assim melhores resultados, o que gera satisfação e estabilidade emocional para todos, principalmente para esses alunos com deficiências. 


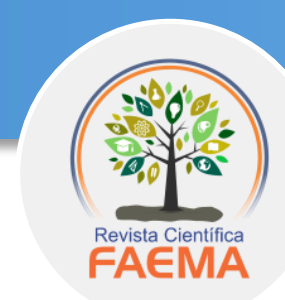

O papel da escola é fundamental para inclusão, seja no conhecimento ou adaptação social, já que é a principal intermediária do aluno na sociedade. Portanto, é de fundamental importância ter um ambiente preparado, para tratar todos igualmente e se adequar a suas diferenças. Esse é o prisma de uma educação inclusiva: ter um ambiente que se adapte às necessidades dos estudantes.

Como bem detalhado, tutelado é garantido pela Constituição Federal, todos sem exceção têm o direito à educação, o que se visa no ordenamento jurídico é uma igualdade para todos, sem exclusão. A Declaração de Salamanca foi de fundamental importância para dar força a este prisma de educação inclusiva, estabelecendo o apoio ao desenvolvimento da educação especial como parte integrante a todos os programas educacionais ${ }^{(16)}$.

Em função disso, as instituições devem constituir-se seguindo essa vertente, trazendo melhorias e garantindo o avanço educacional, pois os métodos de hoje não são eficazes o bastante para suprir o desenvolvimento social que está constantemente se modificando e se reinventando.

O público-alvo desta reforma de inclusão é o aluno, e tendo em vista esta problemática, os alunos com deficiência, declararam que, o contato como os outros alunos e funcionários do corpo docente, todos em um mesmo ambiente, foi de fundamental importância para transição desta fase de compreensão de convívio social ${ }^{(17)}$.

Assim, o que deve ser levado em conta, quando houver o recebimento de um aluno com deficiência é sua particularidade, para assim definir os meios necessários para sua melhor inclusão ao ambiente educacional. Contudo, existem alguns empecilhos para este processo de inclusão, quando se há falta de profissionais capacitados, investimentos em infraestrutura e materiais necessários ${ }^{(18)}$. 
É necessário desenvolver um ambiente que não seja focado exclusivamente em suas necessidades, a fim de estabelecer um ambiente de acolhimento onde todos usufruem dos mesmos espaços. O que estas pessoas buscam é a autonomia, a sensação de capacidade e independência, por isso, ao se disponibilizar os meios necessários como os materiais, terão chegado ao objetivo de igualdade.

Este desejo não é de agora, ao longo de toda história, a deficiência era vista como "mau agouro", as pessoas com deficiência eram tidas como incapazes de fazer qualquer coisa, sendo completamente e totalmente dependentes de seus familiares. Fundou-se um perfil ideal de “pessoal normal” e essas pessoas segundo a história não se encaixavam ${ }^{(18)}$. Em consequência disso, a discriminação frente a ignorância só aumentou, todavia, a partir do século XX começou a modificação desta realidade, com melhor compreensão e aceitação à pessoa com deficiência. Assim, para que continue com esta rotatividade evolutiva, se faz necessário trabalhar em conjunto, políticas, programas, serviços, corpo docente e a comunidade em geral, para deste modo, trazer força ao movimento de inclusão.

O ponto da questão é que não se soluciona um problema somente com elaborações de leis e decretos, haja vista que existem inúmeras leis que tutelam as diretrizes deste direito, contudo se não houver frutos, mudanças em relação a esta vertente, não se atingirá o objetivo almejado.

Para que isto ocorra de uma forma efetiva, deve-se ter uma melhor fiscalização das verbas destinadas a este fim, pois sem recursos, a implantação desta inclusão ficará somente no teórico, além disso, há sempre o risco de a educação não se tornar homogênea, cabe então, focar em sistemas de capacitação para os profissionais que trabalham neste meio, pois é preciso ter em vista que cada criança possui sua particularidade, habilidade e necessidade única, que deve ser atendida para que seu aprendizado seja completo. 
Ademais, como foi anteriormente citado, o método básico de instruir não é mais eficaz, portanto, dinâmicas e atividades extracurriculares diferenciadas que inclua e incite o aluno ao conhecimento, trarão mais efetividade.

Para melhor compreensão do papel da educação inclusiva faz-se necessário primeiramente conceituar o que é Educação. Conforme tratado no artigo $1^{\circ}$ da Lei n $9.394{ }^{(19)}$, Lei de Diretrizes e Base da Educação define que "a educação abrange os processos formativos que se desenvolvem na vida familiar, na convivência humana, no trabalho, nas instituições de ensino e pesquisa, nos movimentos sociais e organizações da sociedade civil e nas manifestações culturais", tal conceito demonstra claramente que a educação não é caracterizada somente pelo processo de ensino-aprendizagem baseado exclusivamente na instrução conteudista, indo além da transferência do conhecimento do professor para aluno. A educação, de acordo com esta definição, está em todas as relações sociais.

Paulo Freire, grande educador e filósofo brasileiro, apud José Junior Souza da Costa (20), afirma que "a educação é sempre uma certa teoria do conhecimento posta em prática", logo, "educação seria criação do conhecimento como processo social resultante da ação-reflexão humana para a transformação da realidade".

José Junior Souza da Costa reflete:

Assim, educação seria uma concepção filosófica e/ou científica acerca do conhecimento colocada em prática. Alguém que praticasse uma concepção de conhecimento estaria 'fazendo' educação. Educar seria promover a prática de uma teoria sobre o conhecimento. Portanto, toda ação com propósitos educacionais estaria necessariamente fundamentada em uma convicção acerca do conhecimento. ${ }^{(20)}$

Conforme mencionado anteriormente, a Lei ${ }^{\circ}$ 9.394/96 define educação e estabelece no $\S 1^{\circ}$ que esta lei disciplinará a educação escolar, que se desenvolve, predominantemente, através do ensino, em instituições próprias (19). 


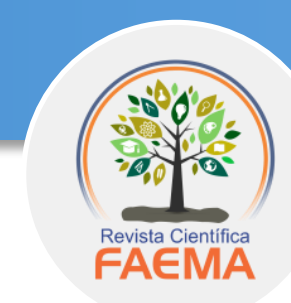

A Constituição Federal, em seu capítulo 3, seção da educação, elenca uma série de dispositivos par a o acesso à educação e que esta seja de qualidade. No artigo 205 é definido que "a educação, direito de todos e dever do Estado e da família, será promovida e incentivada com a colaboração da sociedade, visando ao pleno desenvolvimento da pessoa, seu preparo para o exercício da cidadania e sua qualificação para o trabalho" dando ênfase no artigo 206, I, que tem como princípio à igualdade de condições para o acesso e permanência na escola (7).

O legislador mais do que afirma que a educação é um direito de todos e dever do Estado, que tem como princípio da igualdade, ressalta com veemência no artigo 208, III, da Constituição Federal de 1988 que a educação será efetivada mediante a garantia de atendimento educacional especializado aos portadores de deficiência, preferencialmente na rede regular de ensino ${ }^{(7)}$.

A Lei $n^{\circ} 9.394^{(19)}$, em seu capítulo V, versa sobre a educação especial. Conforme o artigo 58 "é a modalidade de educação escolar oferecida preferencialmente na rede regular de ensino, para educandos com deficiência, transtornos globais do desenvolvimento e altas habilidades ou superdotação". Verifica-se assim que a educação será oferecida para todos independente de suas limitações, adotando a inclusão escolar das pessoas com deficiência, e em condições de igualdade com os demais alunos. De acordo com o artigo $2^{\circ}$ da Lei $n^{\circ} 13.146$ (21):

Considera-se pessoa com deficiência aquela que tem impedimento de longo prazo de natureza física, mental, intelectual ou sensorial, o qual, em interação com uma ou mais barreiras, pode obstruir sua participação plena e efetiva na sociedade em igualdade de condições com as demais pessoas.

Assim sendo, a inclusão escolar é o acesso e a permanência de todos os cidadãos na escola, sendo ele deficiente ou não, possibilitando a convivência com os demais estudantes, local este que permitirá a experiência da diversidade, contudo com igualdade de condições com os demais. Inclusão não é somente a matrícula ou 
o acesso, mas a interação com os demais, portanto, a escola deverá quebrar as barreiras que obstruem essa participação.

O decreto de $\mathrm{n}^{\circ} 7.611^{(22)}$ dispõe sobre a educação especial, o atendimento educacional especializado e dá outras, no qual dispões diretrizes para que a educação especial seja efetivada, como descreve os seguintes incisos do artigo $1^{\circ}$ :

I - Garantia de um sistema educacional inclusivo em todos os níveis, sem discriminação e com base na igualdade de oportunidades;

II - Aprendizado ao longo de toda a vida;

III - Não exclusão do sistema educacional geral sob alegação de deficiência;

IV - Garantia de ensino fundamental gratuito e compulsório, asseguradas adaptações razoáveis de acordo com as necessidades individuais;

V - Oferta de apoio necessário, no âmbito do sistema educacional geral, com vistas a facilitar sua efetiva educação;

VI - Adoção de medidas de apoio individualizadas e efetivas, em ambientes que maximizem o desenvolvimento acadêmico e social, de acordo com a meta de inclusão plena;

VII - Oferta de educação especial preferencialmente na rede regular de ensino; e

VIII - Apoio técnico e financeiro pelo Poder Público às instituições privadas sem fins lucrativos, especializadas e com atuação exclusiva em educação especial.

E acrescenta ainda,

Art. $2^{\circ}$. A educação especial deve garantir os serviços de apoio especializado voltado a eliminar as barreiras que possam obstruir o processo de escolarização de estudantes com deficiência, transtornos globais do desenvolvimento e altas habilidades ou superdotação. [...] $\S 2^{\circ} \mathrm{O}$ atendimento educacional especializado deve integrar a proposta pedagógica da escola, envolver a participação da família para garantir pleno acesso e participação dos estudantes, atender às necessidades específicas das pessoas público-alvo da educação especial, e ser realizado em articulação com as demais políticas públicas. ${ }^{(22)}$ 
De acordo com a Resolução $n^{\circ} 4{ }^{(23)}$ que Institui Diretrizes Operacionais para o Atendimento Educacional Especializado na Educação Básica, modalidade Educação Especial:

Os sistemas de ensino devem matricular os alunos com deficiência, transtornos globais do desenvolvimento e altas habilidades/superdotação nas classes comuns do ensino regular e no Atendimento Educacional Especializado (AEE), ofertado em salas de recursos multifuncionais ou em centros de Atendimento Educacional Especializado da rede pública ou de instituições comunitárias, confessionais ou filantrópicas sem fins lucrativos.

Ao disciplinar a educação escolar, vinculando ao mundo do trabalho e à prática social, considerando como direito de todos, dever do estado, da família e de toda sociedade, o legislador propicia o pleno desenvolvimento, devendo ser respeitada e cumprida. Ao regulamentar a oferta, cria-se assim formas de execução da lei, permitindo o seu funcionamento.

Fazendo referência à Freire, esse processo de inclusão escolar propicia uma ação de reflexão humana capaz de transformar a sociedade. Uma vez que a inclusão social não é vista na modalidade de transferência de conhecimento, mas sim um ambiente que o perpassa, abrangendo de fato o que se define na Constituição Federal, LDB e Estatuto das pessoas com deficiência, todavia, mais do que garantir, evidencia que é imprescindível que a legislação avance na sua executoriedade. Paralelo a isso é fundamental a participação da família e de toda sociedade neste processo, contribuindo com este acesso e permanência (20).

A educação inclusiva é direito constitucional, e mais do que direito de se matricular, o aluno tem direito de ter um ensino de qualidade. Este deve ser garantido pelo estado, independente da deficiência do aluno. Neste contexto, propiciar ao aluno com deficiência o exercício de sua cidadania, uma vez que, possibilitará a formação dita formal (currículo escolar) bem como sua socialização, garantindo o desenvolvimento de suas capacidades e transformando sua história e a 
sociedade. Essa transformação tem como prisma uma sociedade menos seletiva e mais inclusiva. O Estatuto da pessoa com deficiência, instituído pela Lei 13.146/2015 (21), determina que a educação é um direito da pessoa com deficiência, e que deve ser prestada pelo Estado, comunidade escolar, assim como, pela família.

A educação constitui direito da pessoa com deficiência, assegurados sistema educacional inclusivo em todos os níveis e aprendizado ao longo de toda a vida, de forma a alcançar o máximo desenvolvimento possível de seus talentos e habilidades físicas, sensoriais, intelectuais e sociais, segundo suas características, interesses e necessidades de aprendizagem. (21)

O Estado tem a competência para incluir as pessoas com deficiências na rede de ensino público, sendo auxiliado pelas famílias, a fim de lhes proporcionar uma educação de qualidade, e um tratamento digno humanizado.

Dados do Censo Escolar 2018, divulgados pelo Instituto Nacional de Estudos e Pesquisas Educacionais Anísio Teixeira - INEP -, apontou um aumento de 33,2\% (trinta e três inteiros e dois décimos por cento) de matrículas de estudantes com necessidades especiais entre 2014 e 2018. De acordo com um estudo feito pelo Instituto, há cerca de 1,2 (um milhão e duzentos mil) milhão de alunos com deficiência, superdotados e transtornos a nível internacional. A educação inclusiva, ocorre na maioria dos casos em escola públicas, onde dados apontam que o total de alunos com necessidades especiais correspondem a 97,3\% (noventa e sete inteiros e três décimos por cento) na rede pública e 51,8\% (cinquenta e um inteiros e oito décimos por cento) na rede particular. Além disso, a educação inclusiva comporta a infraestrutura das escolas para atender as necessidades dos alunos (10).

A inclusão de alunos com algum tipo de necessidade especial na rede pública de ensino de Rondônia, ainda é um desafio, contudo vem se aumentando os índices de matrículas nos últimos anos, segundo dados do governo estadual, no ano de 2012, eram cerca de 3.608 (três mil, seiscentos e oito) alunos matriculados, passando em 2016 para 5.204 (cinco mil, duzentos e quatro) estudantes na rede estadual de ensino (24). 


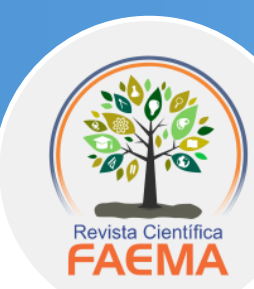

Outrossim, o programa de escola acessível, implantado nas escolas estaduais pelo governo de Rondônia, por meio da coordenadoria da educação especial, da Secretaria de Estado da Educação - SEDUC/RO, sendo desenvolvido em 319 (trezentos e dezenove) escolas estaduais, totalizando 299 (duzentos e noventa e nove) salas de aulas atendidas pelo programa. Nessas salas de aulas são trabalhados com os alunos o Braile, a informática, a ampliação da fonte de prova para alunos com baixa visão, além de vários outros recursos que visam facilitar o aprendizado a esses estudantes. As estratégias que compõem o atendimento educacional especializado nesses ambientes proporcionam aos estudantes o uso de ferramentas pedagógicas que contribuem para desenvolvimento cognitivo e aprendizagem (24).

Outro ponto, é a adaptação das estruturas físicas das escolas para que os espaços não sejam obstáculos aos estudantes. Além do que, foram oportunizados cursos de capacitação aos profissionais, assim como, a contratação de novos profissionais, por meio de concurso público, a fim de que as escolas possam proporcionar aos estudantes com necessidades especiais um atendimento pautado na dignidade da pessoa humana, preparando-os para uma convivência de equidade com os demais alunos ${ }^{(24)}$.

Com o advindo da pandemia do coronavírus decretada pelo Governo Federal em março de 2020, o cenário da educação brasileira mudou abruptamente, quando as escolas de todo País foram fechadas, passando para o ensino a distância, haja vista, por conta das restrições sanitárias para combater a proliferação do vírus, os alunos não podem frequentar as aulas de forma presencial, tendo que adaptar-se ao modelo virtual.

As atividades pedagógicas não presenciais aplicam-se aos alunos de todos os níveis, etapas e modalidades educacionais. Portanto, é extensivo àqueles submetidos a regimes especiais de ensino, entre os quais os que apresentam altas habilidades/superdotação, deficiência e Transtorno do Espectro Autista (TEA), atendidos pela modalidade de Educação Especial. ${ }^{(25)}$ 


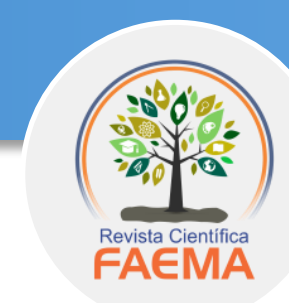

Essa situação ficou mais preocupante ainda, em relação aos alunos com necessidades especiais, pois eles precisam de atenção diferenciada pelos professores, com isso o Conselho Nacional de Educação - CNE, aprovou parecer garantindo a assistência e os métodos de ensino a distância a todos os alunos da rede pública e privada ${ }^{(25)}$.

Em suma, as aulas com ensino a distância, mediadas ou não por tecnologias digitais e comunicação, utilizaram medidas de acessibilidade igualmente a todos, enquanto perdurar a impossibilidade de aulas presenciais nas escolas do ensino básico e superior onde estejam matriculados os estudantes com necessidades especiais ${ }^{(25)}$.

Por derradeiro, os Estados, o Distrito Federal e os Municípios deverão assegurar medidas locais que garantam a oferta do ensino, recursos e estratégias para que os atendimentos dos estudantes da educação especial ocorra com qualidade satisfatória, garantindo o Atendimento Educacional Especializado (AEE) no período de emergência, mobilizado e orientado por professores regentes e especializados, em coordenação com as famílias para a realização das atividades escolares virtuais a serem disponibilizadas ${ }^{(25)}$.

Tendo em vista os dados apresentados, é mais que notável a preocupação em preparar e trazer o aluno deficiente para as escolas, garantindo os recursos e apoios necessários para que possam ter um aprendizado de qualidade, bem como atentarse na relação que o aluno e o professor estabelecem.

A maneira que o professor e o aluno se relacionam cria a afetividade fazendo com que a relação se fortaleça cada vez mais. O aprendizado do aluno se dá no cotidiano, já que é através da prática que se constrói conhecimento. Pode ser que o significado da palavra incluir, não esteja ligado a inserir pessoas diferentes na sociedade, mas sim em fazer um trabalho diferenciado com essas pessoas. Para que a inclusão se concretize, faz-se necessário rever a forma em que as escolas se organizam e como colocam em prática os princípios da educação inclusiva (26). 


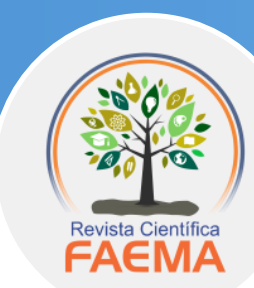

Por isso, entende-se que o relacionamento entre o corpo docente e discente das instituições de ensino, são tão almejados para garantir a eficácia da compreensão das atividades praticadas em sala de aula.

Os professores devem modificar a sua prática, porque por mais inclusivo que ele seja, não consegue incluir o aluno sozinho, sendo assim é importante e fundamental a participação do aluno diante a comunidade. A inclusão não acontece em um mês ou a cada semestre, mas sim todos os dias, o professor deve assumir um compromisso com planejamento a todos sem qualquer distinção, então o educador especial em sala de aula tem que estar atento às necessidades dos alunos ${ }^{(26)}$. Neste caso, a educação inclusiva carece de maior aperfeiçoamento, não sendo somente obrigação dos professores e da família, mas sim da sociedade como um todo.

O professor da educação especial não deve ser diferente dos demais professores, ambos devem inserir todos os alunos independente do planejamento de aula. Para obter resultado, o educador especial tem que ser transmissor do direito do aluno deficiente mostrando meios que os insira na sociedade ${ }^{(26)}$. Nota-se que a união dos docentes é de tamanha importância, pois sozinho o educador especial ainda terá dificuldades na inclusão do aluno, devendo todos os professores estarem unidos e garantir o aprendizado, dando apoio a todos os alunos, sem qualquer distinção.

A sociedade é composta por pessoas de vários tipos, culturas, raças, etnias e na escola não pode ser diferente, já que levantasse a bandeira que ninguém é igual a ninguém. Reitera-se que para uma educação de qualidade faz-se necessário uma formação sólida e contínua para que aconteça uma progressão na inclusão do aluno especial (26). É importante pensar no professor como agente de transmissor que respeita as diferenças, compreendendo e respeitando que cada aluno reage de forma diferente de acordo com sua personalidade ${ }^{(26)}$. 


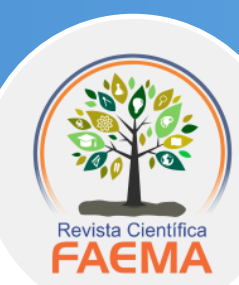

Ocorre ainda, uma grande resistência das escolas em receber alunos inclusos devido à falta de experiência que diversos profissionais enfrentam, não sabendo se o aluno vai ou não se encaixar naquele perfil de sala antes mesmo de saber quais são suas limitações ${ }^{(26)}$.

Em relação a formação de um aluno especial, não só como professores, mas com os responsáveis por essas crianças, há reclamações da falta de suporte aos profissionais da área da especificidade para trabalhar e até mesmo desenvolver um bom método pedagógico. Não só é importante a formação do professor e o preparo em sala de aula em prol do desenvolvimento do aluno incluso, mas também para entender as diferenças de cada um, oferecendo uma boa aplicação tanto na sala de aula, quanto na sala de recursos que é um espaço que o professor especializado realiza a complementação ou suplementação curricular, fazendo uso de equipamentos específicos (26).

0 professor deve estar cercado de outros profissionais para que de fato a inclusão aconteça, para que o aluno desenvolva um avanço naquele grau da sua deficiência. É de suma importância ainda que os demais professores, mesmo que não especializados na área educacional especial, desenvolvam métodos em sala de aula, fazendo com que outros alunos vejam ou revejam o grau de dificuldade dos alunos especiais em estar diante a sociedade, mas que não é algo impossível (26).

Uma vez que o profissional da educação especial esteja aberto e busca meios para interagir com o diferente, este poderá contribuir para uma equiparação preparando-o para sociedade na qual seus limites e possibilidades serão respeitados dentro de suas capacidades, podendo também interagir com os "ditos" normais sem causar quaisquer prejuízos pessoais e sociais a eles trazendo conforto em estar em meio a comunidade ${ }^{(26)}$. 
É nítido a grande dificuldade dos professores que ministram aulas em salas com alunos inclusos, bem como a dificuldade de adaptação dos docentes aos conteúdos e a metodologias. Apesar da sala de recursos, docentes enfrentam desafios em suas práticas pedagógicas que dificultam seu trabalho, como a falta de formação adequada, salas numerosas, questões que influenciam muito na docência e prejudicam a inclusão dos alunos, sendo preciso paciência e como já referido acima, planejamento ${ }^{(26)}$.

Diante desse panorama há a percepção de docentes que fazem o que é possível, aplicando o que a escola sugere, com os únicos materiais que possuem que comprometem o processo de inclusão. Independente de todas as circunstâncias, nota-se um grande avanço em direção a inclusão, mesmo que ainda haja um longo caminho a percorrer, existe uma quantidade de docentes garantindo a escolarização de seus alunos especiais singularizando e possibilitando o aprendizado e a desenvoltura, evitando lacunas destes na sociedade. Ressaltando que a dificuldade do aluno em se aceitar pode apontar uma grande fragilidade na formação pedagógica, a aceitação do aluno é o primeiro passo para a construção do vínculo com o docente ${ }^{(26)}$.

É de suma importância a participação e a colaboração de todos os envolvidos, pois assim facilita o aprendizado do aluno em sala de aula, por isso, a formação dos professores que são responsáveis por prestar assistência a estes alunos é um dos requisitos mais que necessário para a inclusão destes alunos.

\section{Conclusões}

Este artigo abordou sobre a importância da inclusão dos alunos com deficiência, tanto na rede pública como privada. Fora apresentado nesta pesquisa que, desde a década de 1970, o Brasil passou a implantar as escolas inclusivas, porém muito antes disso o País já prestava auxílio a pessoas com deficiência auditiva, visual ou quaisquer outras. 


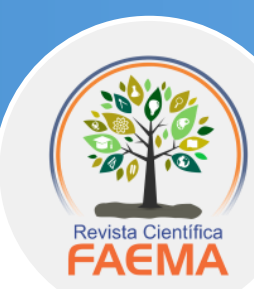

Constatou-se que a participação da família, dos professores especiais, bem como dos demais alunos que cercam o aluno com deficiência, e da sociedade são de tamanha importância no desenvolvimento e aprendizado, além de se sentirem acolhidos e capazes de aprender cada vez mais.

Por mais que ainda haja um longo caminho para total inclusão e total acesso escolar de crianças com deficiência, a legislação brasileira tem se preocupado em trazer cada vez mais programas de apoio e inclusão das famílias e das escolas, pois como a educação é tratada como direito Constitucional, não se pode deixar estas crianças sem nenhum tipo de apoio. Foi mais que notável, que qualquer aprimoramento dos materiais didáticos, profissionalização especial para os professores que irão cuidar destes alunos e o amparo a essas famílias geram resultados mais que satisfatórios na vida escolar dos alunos, mas ainda assim, há um longo caminho a percorrer para garantir que todos tenham devida assistência.

Apresentou-se, diante disso, como solução jurídica, maior implementação de programa de educação inclusiva nas redes de ensino, formar cada vez mais professores para serem educadores especiais, além de promover a interação e apoio mútuo entre os professores, disponibilizar mais recursos didáticos para os alunos, garantir maior acesso de crianças em escolas, pois é de fácil compreensão as dificuldades dos pais em encontrar instituições que tenham infraestrutura, seja nas formas de conteúdo ou na locomoção destes, capazes de receber e suprir as necessidades dos alunos com deficiência.

Para finalizar, espera-se que todos, as famílias, os professores, os legisladores e os próprios alunos, se unam e garantam a maior eficácia no aprendizado e acolhimento dos alunos com deficiência, sem nenhum tipo de impedimento seja na infraestrutura ou no material que será dado ao aluno para que possa dar início e continuidade a sua vida estudantil. Pois, como descrito na Constituição Federal, todos têm direito à educação, sendo este um dos direitos sociais, além de ser dever do Estado perante a educação. 


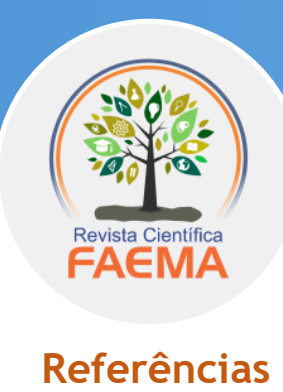

1. Knechtel MR. Metodologia da pesquisa em educação: uma abordagem teóricoprática dialogada. Curitiba: Intersaberes, 2014.

2. Lando F. Pesquisa exploratória, descritiva ou explicativa. Publicado em: 2020. Disponível em: https://www.academicapesquisa.com.br/post/pesquisaexploratoria-descritiva-explicativa.

3. Tumelero N. Pesquisa bibliográfica: material completo com 5 dicas fundamentais. Publicado em: 2019. Apud Fonseca, JJS. Metodologia da pesquisa científica. Fortaleza: UEC, 2002. Disponível em:

https://blog.mettzer.com/pesquisa-bibliografica/.

4. Ferrari M. Célestin Freinet, o mestre do trabalho e do com senso. Nova Escola. Disponível em: https://novaescola.org.br/conteudo/1754/celestin-freinet-omestre-do-trabalho-e-do-bom-senso. Publicado em: 2008.

5. Souto MT de. Educação inclusiva no Brasil: Contexto histórico e contemporaneidade. Universidade estadual da Paraíba, Centro de ciências e tecnologia, Departamento de Química. Disponível em:

http: / /dspace.bc.uepb.edu.br/jspui/bitstream/123456789/5051/1/PDF\%20\%20Maric\%C3\%A9lia\%20Tom\%C3\%A1z\%20de\%20Souto.pdf. Publicado em: 2014; Campina Grande - PB, 2014.

6. Diversa. Conceitos fundamentais. Instituto Rodrigo Mendes. Diversa educação inclusiva na prática. Disponível em: https://diversa.org.br/educacao-inclusiva/poronde-comecar/conceitos-fundamentais/. Publicado em: 2017.

7. Brasil. Constituição da República Federativa do Brasil. Brasília: Senado, 1988. Disponível em:

http://www.planalto.gov.br/ccivil_03/constituicao/constituicaocompilado.htm.

8. Ministério da Educação. Política nacional de educação especial na perspectiva da educação inclusiva. Ministério da Educação. Disponível em:

http://portal.mec.gov.br/component/tags/tag/31872-educacao-inclusiva.

Publicado em: 2008.

9. UNESCO. Declaração de Salamanca e linha de ação sobre necessidades educativas especiais. Brasília: UNESCO, 1994. Disponível em:

http://portal.mec.gov.br/seesp/arquivos/pdf/salamanca.pdf. 
10. Silva G. Cresce o número de matrículas dos estudantes com necessidades especiais. Educa Mais Brasil. Disponível em: https://www.educamaisbrasil.com.br/educacao/noticias/cresce-o-numero-dematriculas-dos-estudantes-com-necessidades-especiais. Publicado em: 2019.

11. Souza F. Educação para todos sob a ótica da inclusão escolar exigências e diretrizes. BRASIL ESCOLA. Disponível em:

https://monografias.brasilescola.uol.com.br/educacao/fabiana-souzaaraujoeducacao-para-todos-sob-otica-inclusao-escolar-exigencias-diretrizes.htm. Publicado em: 2019.

12. Escolaweb. Deficiência intelectual: ótimas dicas para ensinar estes alunos. WAKKE. Disponível em: https: //wakke.co/deficiencia-intelectual-otimas-dicaspara/. Publicado em: 2016.

13. Curso de direito da criança e do adolescente: aspectos teóricos e práticos / Andréa Rodrigues Amin [et. al]; coordenação de Kátia Regina Ferreira Lobo Andrade Maciel. - 13. ed. - São Paulo: Saraiva Educação, 2021.

14. Cerqueira-Silva S; Dessen MA. Relações familiares na perspectiva de pais, irmãos e crianças com deficiência. Revista Brasileira de Educação Especial, 20(3), 421-434, 2014. Disponível em: https://www.scielo.br/pdf/rbee/v20n3/07.pdf.

15. Kelman, CA; Amparo M do. Desenvolvimento Humano, Educação e Inclusão Escolar. Capítulo 1 Sociedade, educação e cultura, p. 15-58. Disponível em: https://www.academia.edu/26759600/Desenvolvimento_Humano_Educa\%C3\%A7\%C 3\%A3o_e_Inclus\%C3\%A3o_Escolar_2a_ed_2015_. P. 15-58.

16. Ministério da Educação. Declaração De Salamanca: Sobre princípios, políticas e práticas na área das necessidades educativas especiais. Salamanca - Espanha, 1994. Ministério da Educação. Disponível em: http://portal.mec.gov.br/seesp/arquivos/pdf/salamanca.pdf.

17. Governo do Estado de São Paulo. Relatório mundial sobre a deciência / World Health Organization, The World Bank; tradução Lexicus Serviços Lingüísticos. - São Paulo: SEDPCD, 2012. Disponível em: https://apps.who.int/iris/bitstream/handle/10665/44575/9788564047020_por.pdf; jsessionid=4BE25580AF5652BB9EB3CB8BEE4C4F43? sequence $=4$. 
18. Amorim, JM. Os desafios da inclusão escolar no ensino regular público de barra do garças - mt: algumas considerações. Monografias Brasil Escola. Disponível em: https://monografias.brasilescola.uol.com.br/educacao/os-desafios-inclusaoescolar-no-ensino-regular-publico-barra.htm. Publicado em: 2016.

19. Brasil. Lei $n^{\circ} 9.394$, de 20 de dezembro de 1996. Planalto Disponível em http://www.planalto.gov.br/ccivil_03/leis/19394.htm. Acesso em: 16 abr. 2021.

20. Costa, JJS da. A educação segundo Paulo Freire: uma primeira análise filosófica. Theoria - Revista Eletrônica de Filosofia. Volume VII, n. 18, ano 2015. Faculdade Católica de Pouso Alegre. Disponível em: https://www.theoria.com.br/edicao18/06182015RT.pdf. P: 10, 73 e 75.

21. Brasil. Lei 13.146 de 6 de julho 2015. Planalto. Disponível em: http://www.planalto.gov.br/ccivil_03/_ato2015-2018/2015/lei//13146.htm.

22. Brasil. Decreto $n^{\circ} 7.611$, de 17 de novembro de 2011. Planalto. Disponível em: http://www.planalto.gov.br/ccivil_03/_ato2011-2014/2011/decreto/d7611.htm.

23. Ministério da Educação. Resolução $n^{\circ} 4$, de 2 de outubro de 2009. Ministério da Educação. Disponível em:

http: //portal.mec.gov.br/index.php?option=com_content\&view=article\&id=13684\% 3Aresolucoes-ceb.

24. Governo de Rondônia. Investimento em profissionais e equipamentos promove a inclusão de crianças e jovens em escolas da rede estadual de Rondônia. Disponível em: http: / /www.rondonia.ro.gov.br/investimento-em-profissionais-eequipamentos-promove-a-inclusao-de-criancas-e-jovens-em-escolas-da-redeestadual-de-rondonia/. Publicado em: 2017.

25. Ministério da Educação. PARECER CNE/CP N: 5/2020. Ministério da Educação. Disponível em:

http: / / portal.mec.gov.br/index.php?option=com_docman\&view=download\&alias=1 45011-pcp005-20\&category_slug=marco-2020-pdf\&ltemid=30192. Publicado em: 2020. P: $14-15$

26. Silva A; Arruda A. O Papel do Professor Diante da Inclusão Escolar. Revista Eletrônica Saberes da Eletrônica, São Roque/SP, v. 5, n. 1. Disponível em http://docs.uninove.br/arte/fac/publicacoes_pdf/educacao/v5_n1_2014/Ana_Paul a.pdf. Publicado em: 2014. 